linguistics, semiotics and semantics. His cognitive programme is to geometrize thought itself, using the elementary catastrophes as logoi, the algebraico-geometrical structures which stabilize concepts in mental activity space. Semantics is based upon approximate isomorphisms between logoi of material beings and those of the corresponding concepts, and so mind perceives real properties of objects which are the "bearers of meaning". His objective is then "to create a theory of meaning whose nature is such that the act itself of knowing is a consequence of the theory; i.e., when an appearance appears to us as a bearer of meaning, we will know why and to what formal facts to attribute it".

What people have primarily reacted against in Thom's writing is the highly discursive style combined with the sharplydefined analytical tools of abstract mathematics. We are used to having mathematics applied to specific problems, leading to solutions. Thom applies it to perennial philosophical and scientific problems, leading to further questions. Clearly catastrophe theory works in physics, where singularity theory worked before, and it is clear how to apply it following that lead. This is the path of wisdom Arnold recommends and illustrates. No one has yet shown how to apply catastrophe theory to the general problems of morphogenesis, cognition and the new physics in the style of a generative science of form suggested by Thom. Until it is tried, it seems premature to condemn it - but no one should be in any doubt about the difficulty of such a programme.

Brian Goodwin is Professor of Biology at the Open University.

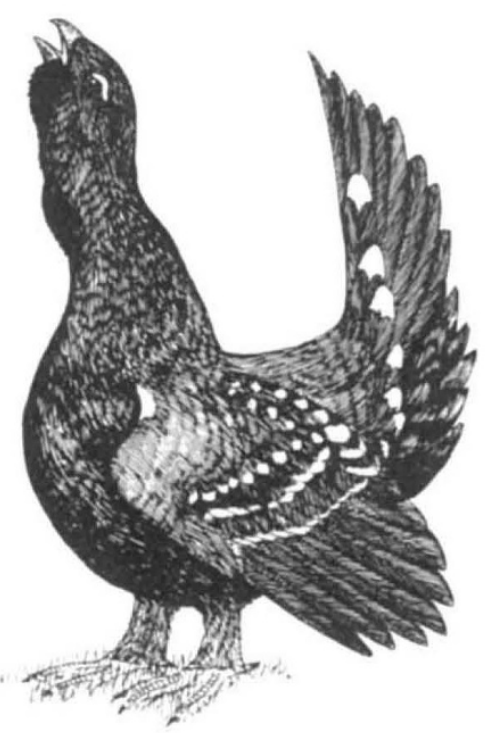

Thin-nccked upright display posture of the male black-billed capercaillie. The drawing is reproduced from Paul A. Johnsgard's The Grouse of the World, published by the University of Nebraska Press in the United States and Croom Heln in Britain. Price is $\$ 42.50, £ 30$.

\section{Sense of energy}

\section{Ian Smart}

Sun Traps. By John Elkington.

Penguin/Viking: 1984. Pp.400.

Pbk £3.95, \$6.95.

EMBEDDED in Mr Elkington's chapters, on fossil fuels and nuclear power as well as renewable energy sources, there is a feast of fact, from a photovoltaic hat to the mass of firewood needed to dry a kilogram of ginger. Like many "popular" energy books, this one tries to handle an astonishing range of topics by assembling anecdotes about all of them, larded with numbers and speckled with names. It is described as a "comprehensive survey on solar power and future energy". But honest efforts to follow the thread of argument through the labyrinth are repeatedly foiled: diverted into yet another garden of colourful trivialities, or distracted by dramatic writing in the "little-did-he-know-that" tradition.

None of this prevents $\mathrm{Mr}$ Elkington from being informative. Nor, which is more important, does it hide his good sense - although it sometimes overshadows it. He begins by pointing out that technical feasibility is no substitute for - or index to - economic competitiveness. And he ends with a studiedly moderate estimate of the contribution renewable sources will make to world energy supply in any of our lifetimes. His assessment could only have been reinforced by more persistent attention to

\section{Walk in the gardens}

\section{George Oster}

\section{An Introduction to the Physical \\ Chemistry of Biological Organization.}

By A.R. Peacocke.

Clarendon: 1983. Pp.302. £35, \$65.

FoRMALISMS are seductive sirens, for they seem to unify so many disparate threads and they promise deep insights using only mathematical manipulations. Of these seductresses, surely thermodynamics is the most alluring. One of its foremost practitioners, the late Aharon Katchalsky, once observed wryly that "it is such a marvelous tool: you don't know what you put in, and you don't understand what you get out. But you know it must be right!".

In physics and chemistry, thermodynamics has performed as advertised; however, in biology it has yet to live up to its billing. By now, no one expects living systems to disobey the laws of thermodynamics, but these tenets are crude and vague constraints when applied to such systems, and they provide very little insight into the operation of biological entities. Nonequilibrium thermodynamics, by economics. As it is, its moderation serves to highlight the euphoric exaggeration by so many of the sun, wind and wave enthusiasts from whom he quotes: a habit of hyperbole matching the former excesses of nuclear apostles and inviting a similar fate.

Mr Elkington himself gets the balance about right, by characterizing as only slightly optimistic a Worldwatch Institute projection that the renewable contribution to global energy supply will rise from $16.5 \%$ in 1980 to $23.9 \%$ in 2000 - with three-quarters of the increase coming from hydroelectricity, geothermal power and fuelwood. $\mathrm{He}$ is no less right to insist that solar-based energy, exploited at reasonable cost and applied in appropriate ways, must make a larger contribution to human welfare. Unfortunately, he barely touches on the fundamental problems involved: the political and economic tension between centralized renewable energy systems, using "high" technology, and decentralized networks, seeking social as well as technical simplicity; the need to choose between ecologically incompatible interests (as between nature conservation and biomass development); and the ultimate dilemma of whether energy should be converted to accommodate society's demands, or social preferences adapted to efficient energy conversion. It is a pity he did not sacrifice more of his anecdotal scrapbook to exploring them. For, through these thickets of lore, there shine rays of a judicious realism.

Ian Smart is an independent adviser on international energy policy affairs, based in London.

extending the venue of classical thermostatics into the realm of dynamics, promised to deliver new understanding and unifying concepts which could shed light on the mysteries of biological organization. But has it? Well, that is a matter of dispute, and reasonable scientists can disagree - although on this subject they usually do so with righteous zeal.

Clearly, Professor Peacocke feels that the sirens' song is worth pursuing, for he devotes the first half of his book to the subject of "Thermodynamic Interpretations of Living Systems". This label is a bit misleading, for discussion of living systems is rarely opened. Only in a few pages of these chapters is any application to specific biological problems attempted, and these attempts consist largely of recasting several biochemical models in the language of network thermodynamics. Beyond a certain notational and conceptual simplification - not to be sneezed at, to be sure - it is not clear that any new understanding emerges.

Chapter 1 commences with a discursive and philosophical excursion into the muddy waters of "complexity" and "hierarchies", finally enunciating the "central problem of biology" as (according to $\mathrm{H}$. Pattee): ". . . the origin and operation of 